\title{
Traumatic rupture of the aortic isthmus: Delayed treatment and open repair - A case report
}

\section{Ruptura traumática del istmo aórtico: retraso en el tratamiento y reparación abierta Reporte de un caso}

\section{Elizabeth Aguilar-Alaníz ${ }^{1 *}$, Rodrigo Reyes-Pavón², José A. Ruiz-Romero', and Javier Esparza-Pantoją}

${ }^{1}$ Department of Cardiovascular Surgery, Centenario Hospital Miguel Hidalgo; ${ }^{2}$ Center of Health Sciences, Universidad Autónoma de Aguascalientes, Aguascalientes, Mexico

Post-traumatic rupture of the aorta is considered a potentially lethal injury since approximately $70-80 \%$ of victims die at the scene, and of the survivors, $30 \%$ will die in the ensuing $24 \mathrm{~h}$. The most common causes include high-speed traffic accidents, explosions, falls from considerable heights, and severe contusions ${ }^{1}$.

A classification of aortic injuries has been proposed, where type I refers to intimal tear, type II to intramural hematoma, type III to pseudoaneurysm, and type IV to rupture with active extravasation².

According to the German Trauma Registry ${ }^{1}$, a prevalence of $1.28 \%$ is calculated, while the incidence of hospitalization for aortic injuries ranges from 2.5 to 4.5/1,000,000 person-years, with type I lesions being more common (approximately $51.6 \%$ ), according to the Canadian National Trauma Registry ${ }^{3}$; in addition, most commonly associated injuries are orthopedic fractures $(68 \%)$ followed by chest injuries (50.5\%) and abdominal injuries (41.3\%), specifically hepatic and splenic injuries ${ }^{4}$.

The case of an aortic blunt trauma is presented, which initially was conservatively managed, with subsequent final open repair at $24 \mathrm{~h}$.

\section{Clinical case}

A 29-year-old male patient, who was ran over by a high-speed motor vehicle. On admission to the emergency room, mild traumatic brain trauma was founब̄ $(12$ points on the Glasgow Coma Scale), the right distal open diaphyseal tibiofibular fracture and closed-chest trauma. His vital signs were blood pressure 130/90, respiratory rate 22 , and heart rate 87 . His laboratory tests showed hemoglobin at $17 \mathrm{~g} / \mathrm{dL}$, hematocrit $53.1 \%$, platelets at 288,000 cells $/ \mathrm{mm}^{3}$, and $1.02 \mathrm{mg} / \mathrm{dL}$ creatinine.

Chest X-ray showed mediastinal widening, trackeal right deviation, and widened aortic knob.

Thoracoabdominal computed tomography (CT) (Fig. 1) revealed right pneumothorax, left pleural effusion, and, as aortic findings, intimal tears, proximal, and distal to the emergence of the left subclavian artery, which delimited the image of a pseudoaneurysm, as well as a periaortic hematoma. In addition, Grade II right renal contusion, Grade III left renal contusion, and right retroperitoneal hematoma were also observed

\section{Correspondence:}

*Elizabeth Aguilar-Alaníz

Departamento de Cirugía Cardiovascular

Centenario Hospital Miguel Hidalgo

Avenida Gómez Morín

Col. La estación Alameda C.P. 2259,

Date of reception: 18-07-2018

Aguascalientes, México

E-mail: eagilar12598@gmail.com
Available online: 06-05-2019 Arch Cardiol Mex (Eng). 2019;89(3):254-257 www.archivoscardiologia.com 2604-7063/@ 2019 Instituto Nacional de Cardiología Ignacio Chávez. Published by Permanyer. This is an open access article under the CC BY-NG-ND license (http://creativecommons.org/licenses/by-nc-nd/4.0/). 


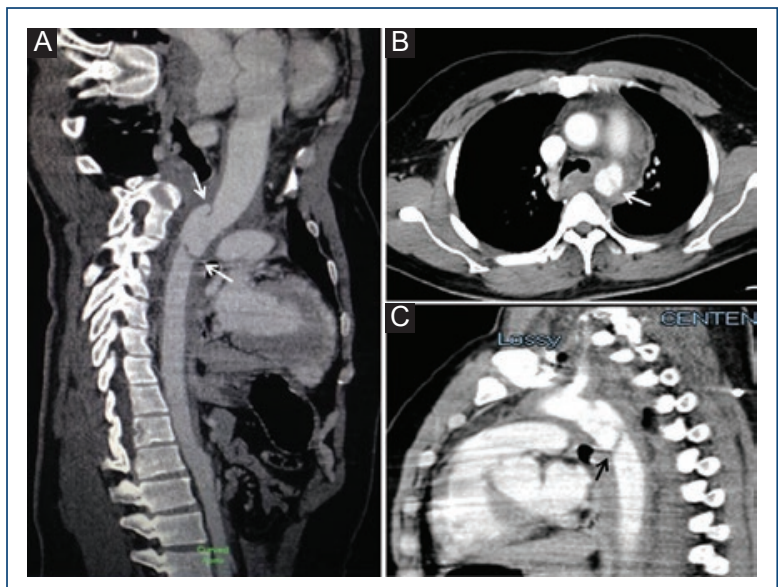

Figure 1. Helical computed tomography angiography with contrast in the arterial phase. A: aortic curve reconstruction (on its longitudinal axis), which shows intimal tears (arrows), proximal and distal to the emergence of the left subclavian artery, which delimit the image of a pseudoaneurysm. B: axial slice at the level of the tracheal bifurcation. Mediastinal and periaortic hematoma (hypodense image, arrow) and intimal tear in the thoracic descending aorta are observed. C: sagittal slice. Intimal tears (arrow) and pseudoaneurysm image.

Interdisciplinary treatment included placement of a left endopleural probe by the department of general surgery, through which $120 \mathrm{~mL}$ of blood were initially drained, as well as fracture immobilization by the trauma department. In view of the CT findings, hypotensive medical management with beta-blocker was started (metoprolol $50 \mathrm{mg}$ every $12 \mathrm{~h}$ ), whereby systolic blood pressure was maintained below 120 and heart rate below 60 for $24 \mathrm{~h}$, after which the patient was brought to the operating room for surgical repair.

Definitive surgical treatment consisted of left posterolateral thoracotomy, with left bypass (from left atrium to left femoral artery), with a type III total section being found at the level of the arterial ligament, contained by the parietal pleura; thus, proximal and distal aortic clamping was performed, the affected segment was sectioned and a $22 \mathrm{~mm}$ wide and $10 \mathrm{~cm}$ long woven Dacron graft was interposed, with a bleeding volume of $1000 \mathrm{~mL}$ and aortic clamping duration of $132 \mathrm{~min}$, after which the patient underwent cardiac arrest that required direct cardiac massage for $33 \mathrm{~min}$, with the patient subsequently recovering vital signs and the left bypass being removed. Admission to the intensive care unit was decided, where he had a torpid immediate evolution since he developed acute respiratory failure syndrome and rhabdomyolysis (with creatine phosphokinase elevation up to 10,934$)$. He showed improvement of both conditions 4 days later, and extubation and discharge to the recovery area were possible, where definitive treatment of the fracture throtigh open reduction and internal fixation was carried out.

A control CT (Fig. 2) showed an interposed graft in the aortic isthmus, and periaortic hematoma resorption, without aortic dilation proximal or distal to the graft.

At 4 days, the patient evolved with a left loculated pleural effusion and respiratory mechanics restriction, and management was decided by thoracoscopy with placement of an endopleural tube, with $300 \mathrm{~mL}$ of serous fluid being drained. The tube was removed 3 days later, and home discharge was decided. In the follow-up visit 8 months after surgery, the patient. Was asymptomatic and with complete recovery.

\section{Discussion}

The imaging study that is routinely used in our medical center (the only one in the state with a cardiothoracic surgery department) is chest contrasted CT sçan, which currently is considered the method of choice for blunt trauma injuries screening and diagnosis $s^{4,5}, \frac{\subsetneq}{\mp}$

The optimal timing to intervene aortic injuries and the decision to address them before or after associated injuries has been the subject of debate for a long time. Taking into account that the risk of traumatic aortic injury rupture is higher within the first $24 \mathrm{~h}$ after the accident, immediate attention was regarded as the standard of care for decades. However, after the publication of the article by Fabian et al. ${ }^{6}$, in 1998, the use of antihypertensive therapeutic approaches became widespread. The success of these approaches to prevent aortic rupture has resulted in the practice of delaying repairs of trauma-related aortic injuries both in high- and low-risk patients. In 2014, the Eastern Association for the Surgery of Trauma $^{7}$ issued an update of its guidelines for the diagnosis and management of aortic damage due to closed chest trauma. Seven studies were included in their analysis, and deferred repair was found to be-associated with lower mortality (relative risk [RR]: ¿07; 95\% confidence intervals [Cl]: 1.03-4.15) and with significantly reduced paraplegia rates (RR: $5.90 ; 95 \% \mathrm{Cl}$ : 1.51-22.97). Although there is no cutoff point regarding the time elapsed between patient hospital admissionand repair surgery that delimits the concepts of "immediate" and "late" (Whal et al. ${ }^{8}$ considered late repair when more than $12 \mathrm{~h}$ have elapsed, Hemmila et al. ${ }^{9}$ spoken about late repair when more than $16 \mathrm{~h}$ have elapsed), current trend is to use controlled hypotensive therapy to plan 

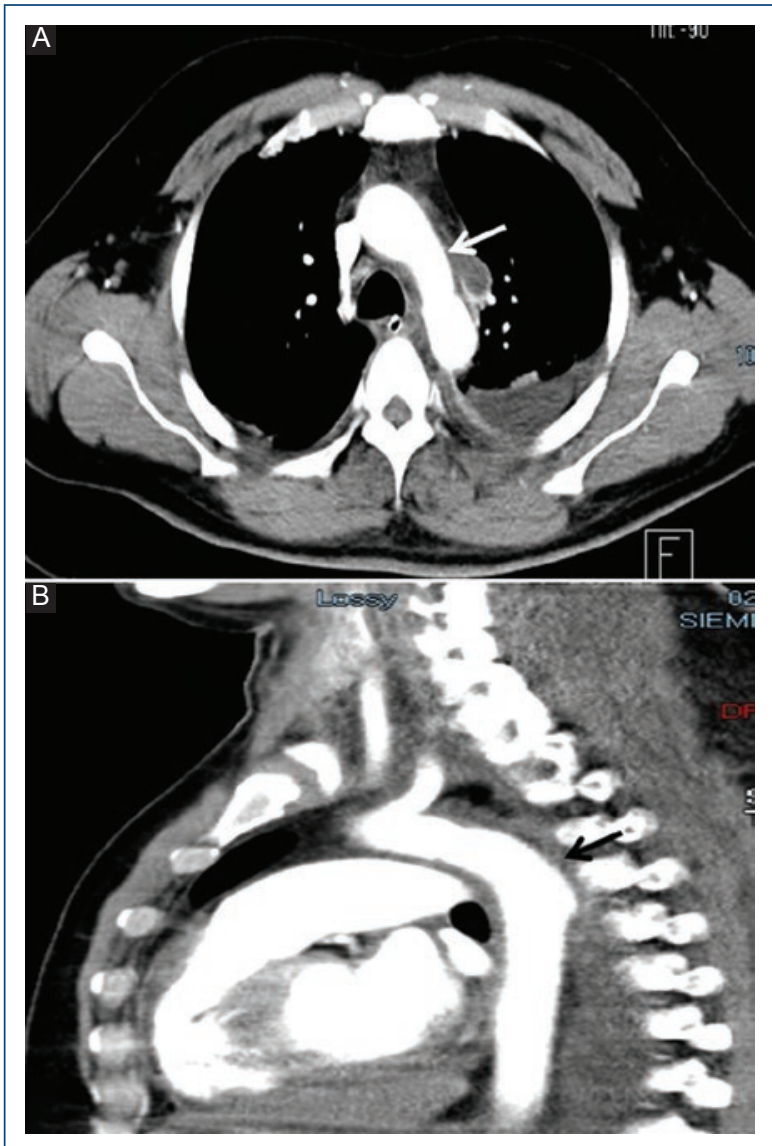

Figure 2. Helical computed tomography angiography with contrast in arterial phase, axial (A) and sagittal (B) sections: properly interposed graft (white and black arrows), with good restoration of aortic continuity and without proximal or distal aortic dilation, as well as periaortic hematoma reabsorption, is observed in both.

repair surgery and avoid an immediate procedure, even in patients where there are no associated injuries that jeopardize life. In our medical center, late management has been chosen whenever possible (never within the first $6 \mathrm{~h}$ of patient hospital admission).

In 2008, a report comparing clinical practice and results between a multicenter prospective study, completed in 1997 (AAST1), and another similar completed in 2007 (AAST2), was published. Comparing both studies, three main changes were observed: first, that the time elapsed since patient admission until definitive repair significantly increased from AAST1 to AAST2 (16.5 \pm $70.8 \mathrm{~h}$ vs. $54.6 \pm 106.6 \mathrm{~h} ; \mathrm{p}<0.001$ ); second, the rate of paraplegia as a complication related to the procedure was reduced, and third, the definitive repair method went from being exclusively with open techniques in 1997 to predominantly endovascular procedures in
2007 since almost $65 \%$ of the patients were managed with this technique ${ }^{10}$. The latter study showed a significant decrease in early mortality with the endovascular technique in comparison with open repair in patients with or without major injuries associated. On the other hand, the incidence of serious complications related to the endovascular procedure was $20 \%$. Long-term follow-up is still not sufficient to describe the failures or complications that might develop with this approazch. Demetriades et al. ${ }^{11}$ referred to stent leakage asothe main complication, especially in young patients however, device innovations are under development, and in a low-volume hospital like ours, the development of this ability is perhaps more difficult.

\section{Conclusion}

The use of antihypertensive drugs is mandatory in all patients with suspected traumatic aortic injury since they reduce the risk of rupture and allow stabilization and evaluation of other injuries. The use of distal aortic perfusion by means of bypass or atrium-left femoral artery temporary bypass decreases the risk of paraplegia in those patients in whom open repair is decided.

\section{Conflicts of interest}

None.

\section{Funding}

None.

\section{Ethical disclosures}

Protection of people and animal subjects. The authors declare that no experiments were performed on humans or animals for this study.

Confidentiality of data. The authors declare that they have followed the protocols of their work center on the publication of patient data.

Right to privacy and informed consent. The thors have obtained written informed consent of the patients and/or subjects mentioned in the article. The corresponding author is in possession of this document.

\section{References}

1. Gombert A, Barbati ME, Storck M, Kotelis D, Keschenau P, Pape HC Treatment of blunt thoracic aortic injury in Germany-Assesment of the TraumaRegister DGU. PLoS One. 2017;12:e0171837. 
2. Lee WA, Matsumura JS, Mitchell RS, Farber MA, Greenberg RK, Azizzadeh $A$, et al. Endovascular repair of traumatic thoracic aortic injury: clinical practice guidelines of the Society for Vascular Surgery. J Vasc Surg. 2011;53:187-92.

3. De Mestral C, Dueck A, Sharma SS, Haas B, Gomez D, Hsiao M. Evolution of the incidence, management, and mortality of blunt thoracic aortic injury: a population-based analysis. J Am Coll Surg. 2013;216: 1110-5.

4. Antonopoulos CN, Sfyroeras GS, Kallinis A, Kakisis JD, Liapis CD, Petridou ET. Epidemiology of concomitant injuries in traumatic thoracic aortic rupture: a meta-analysis. Vascular. 2014; 22:395-405.

5. Cullen E, Lantz E, Johnson C, Young P. Traumatic aortic injury: CT findings, mimics, and therapeutic options. Cardiovasc Diagn Ther. 2014; 4:238- 44.

6. Fabian TC, Davis KA, Gavant ML, Croce MA, Melton SM, Patton JH Jr, et al. Prospective study of blunt aortic injury: helical CT is diagnostic and hypertensive therapy reduces rupture. Ann Surg. 1991;227:666-76.
7. Fox N, Schwartz D, Salazar JH, Haut ER, Dahm P, Black JH, et al. Evaluation and management of blunt traumatic aortic injury: a practice management guideline from the Eastern Association for the Surgery of Trauma. J Trauma Nurs. 2015;22:99-110.

8. Wahl WL, Michaels AJ, Wang SC, Dries DJ, Taheri PA. Blunt thoracic aortic injury: delayed or early repair? J Trauma. 1999;47:254-9. T

9. Hemmila MR, Arbabi S, Rowe SA, Brandt MM, Wang SC, Taher PA, et al. Delayed repair for blunt thoracic aortic injury: is it really equivalent to early repair? J Trauma. 2004:56:13-23.

10. Demetriades D, Velmahos GC, Scalea TM, Jurkovich GJ, Karmy-Jores R, Teiveira PG, et al. Diagnosis and treatment of blunt thoracic aortic injuries: changing perspectives. J Trauma. 2008;64:1415-8.

11. Demetriades D, Velmahos GC, Scalea TM, Jurkovich GJ, Karmy-Jopes R, Teixeira PG, et al. Operative repair or endovascular stent graft in blunt traumatic thoracic aortic injuries: results of an American Association for the Surgery of Trauma Multicenter Study. J Trauma. 2008;64:561:70. 